\title{
BMJ Open Sharing individual participant data from clinical studies: a cross-sectional online survey among Italian patient and citizen groups
}

\author{
Cinzia Colombo, ${ }^{1}$ Anna Roberto, ${ }^{1}$ Karmela Krleza-Jeric, ${ }^{2,3,4}$ Elena Parmelli, ${ }^{5}$ \\ Rita Banzi ${ }^{6}$
}

To cite: Colombo C, Roberto A, Krleza-Jeric K, et al. Sharing individual participant data from clinical studies: a cross-sectional online survey among Italian patient and citizen groups. BMJ Open 2019;9:e024863. doi:10.1136/ bmjopen-2018-024863

- Prepublication history and additional material for this paper are available online. To view please visit the journal (http:// dx.doi.org/10.1136/bmjopen2018-024863).

Received 21 June 2018 Revised 22 November 2018 Accepted 28 November 2018

Check for updates

(C) Author(s) (or their employer(s)) 2019. Re-use permitted under CC BY-NC. No commercial re-use. See rights and permissions. Published by BMJ.

For numbered affiliations see end of article.

Correspondence to

Dr Cinzia Colombo;

cinzia.colombo@marionegri.it

\section{ABSTRACT}

Objectives To gather knowledge on the current debate, opinions and attitudes of Italian patient and citizen groups on individual participant data (IPD) sharing from clinical studies.

Design Cross-sectional online survey.

Setting and participants A 22-item online questionnaire was sent by email to 2003 contacts of patient and citizen groups in Italy. We received 311 responses, checked for duplicate respondents (16); 295 single groups responded, 280 providing questionnaires eligible for analysis (response rate 15\%). Ninety (32.1\%) dealt with oncology and palliative care, 175 (46.2\%) operated locally or regionally and $136(48.6 \%)$ were involved in clinical research.

Outcome measure Data on Italian patient and citizen groups self-reported knowledge, attitudes and opinions on IPD sharing, mechanisms for IPD access, advantages and risks. Results Half the respondents (144 out of $280,51 \%$ ) had some knowledge about the IPD sharing debate, and 60 $(42 \%)$ stated they had an official position (35 in favour, 19 in favour with restrictions, 2 against, 1 neither for nor against, 3 missing). Nineteen discussed the topic encouraged by this survey; $39 \%$ approved broad access by researchers and other professions and identified information to participants, data de-identification, secure archives, access agreements and sanctions for misuse as important aspects of IPD sharing models. Respondents highlighted re-identification, privacy and re-use of data for purposes that participants do not agree on, as main risks, advancement of innovation and reducing waste in research as main advantages. Around half believed IPD sharing would not discourage study participation.

Conclusions Half the respondents were aware of the debate. Those who had an official position were mainly in favour of IPD sharing. Many supported broad access, asking for conditions important for building trust in entities that handle IPD sharing. Although limited by the low response rate, these findings reinforce the demand for reliable and transparent processes where accountabilities are clear.

\section{INTRODUCTION}

Transparency and access to research data are key features of research policies, as they promote optimal use of the data generated
Strengths and limitations of this study

To our knowledge, this is the first survey about data sharing addressing patient and citizen groups.

- Patients' representatives revised the questionnaire and the survey introduction.

- The sample of respondents may not be fully representative of all Italian patient and citizen groups.

The overall response rate was low $(15 \%)$.

by research projects. Increased access and re-use of data from clinical studies, together with the registration of study protocols and publication of all results, could potentially boost the importance and reliability of information supporting decision-making and, as a final consequence, patients' care.

Individual participant data (IPD) refer to the data recorded for each participant in a study, as opposed to the term 'aggregate data' which refers to information averaged or estimated across all individuals in the study.

Access to IPD from clinical studies could reduce unnecessary duplication and exposure of participants in future trials to avoidable harms, increase research integrity, reduce waste and boost the reliability of evidence used in health decision-making. ${ }^{12}$ It can also improve data re-analysis and pooling and lead to new hypotheses about mechanisms of disease and more effective therapies to be tested. ${ }^{2}$

Interest and discussion about whether or how to make clinical research IPD data available for secondary use outside the boundaries of the researchers who generated them has grown substantially in recent years. Clinical study data sharing has been promoted by many stakeholders, including funders, ${ }^{3}$ researchers, ${ }^{4-6}$ journal editors ${ }^{7}$ and pharmaceutical companies. ${ }^{8}$ 
The few empirical assessments of the efficiency of these initiatives have reported encouraging results, though still suboptimal in terms of trial data actually shared. ${ }^{9-11}$

The primary perspective of these initiatives may differ, as well as the weight placed on the different aspects of the process. However, there is a clear common tendency to increase clinical study data access for re-use, aiming at improving the reliability of evidence needed for health decision-making. The debate has shifted from whether to share to how to develop standards for effectively and safely sharing the data. ${ }^{2}{ }^{12}$ It has been understood for a while that any constructive debate about clinical research data sharing requires the involvement of different actors, including study participants and the general public. ${ }^{13-16}$ Data sharing matters to patients and society, as it improves research transparency and can boost the value of trial participants' data. At the same time, it raises several ethical issues, broadly matching those concerning the sharing and re-use of bio-samples. ${ }^{17}$ Questions include the value of transparency and integrity of data to respect research participants, ${ }^{18} 19$ whether data in clinical studies are a public good, ${ }^{20}$ to whom do they belong, ${ }^{132}$ who should decide on data sharing and secondary use, whether privacy is guaranteed ${ }^{22}$ and what does it mean to provide 'informed consent' considering that future uses of data are not fully predictable.

Citizens, patients and their associations are promoting initiatives to share their data and call for a role in deciding which research questions to address. ${ }^{23} 24$

The growing engagement of patient and citizen groups in healthcare decisions and research promotion gives them an important role in shaping health and research policies, with differences according to the country and setting of reference. ${ }^{25-28}$ They also have a role in providing information to their members and the public, potentially influencing opinions and attitudes. Involving the public and study participants in the discussion about data sharing and re-use is, therefore, necessary, partly to ensure the legitimacy of the proposed practices and systems of governance.

To be effective, any data sharing initiative should consider the opinions, attitudes and perceptions of citizens, patients and their associations and some projects and initiatives on clinical studies data sharing have already included patients' representatives in this discussion. ${ }^{25}$ 29-31

Over the last few decades there has been a steady increase in the number of studies exploring public attitudes or acceptability of secondary uses of health data. ${ }^{32-36}$ In general, these have found widespread, although conditional, support for re-use of data for health research. Benefits to wider society, research done for public interest and trust in the organisations handling data access have been widely considered important for ensuring public support and the acceptability of data sharing. Other conditions are anonymisation, accountability mechanisms to protect against misuse or abuse of data, and perceived autonomy or individual control over how data are used. ${ }^{32}$
A study in a US emergency department and a survey aimed at clinical trial participants in USA reached similar results, with most of the persons agreeing on sharing de-identified data from clinical trials. However, in the former study, a quarter said that they would be less likely to participate in a trial if data were to be shared, and in the latter more than a third were concerned that IPD sharing might make people less willing to participate. ${ }^{3738}$ Patients' reluctance to share their health data is often cited as a major barrier to IPD sharing. However, according to the data, ${ }^{38}$ this seems to be a perception rather than a real barrier. Moreover, the clinical study data sharing scenario is rapidly evolving, with several initiatives launched in recent years that are already making data available for further research. ${ }^{39}$ These studies addressed different targets but, to our knowledge, none specifically aimed at patient and citizen groups. In the light of the actual and potential role of these groups in health and research policies, we ran an online survey to collect specific information on Italian patient and citizen groups' views about IPD sharing from clinical studies. We aimed to gather knowledge on the current debate, opinions, that is, what patient and citizen groups think about this issue, and attitudes, that is, their intentions for behaviour. We launched the survey also to arouse interest in this topic and foster a discussion in invited patient and citizen groups.

\section{METHODS}

\section{Survey questionnaire}

The survey was planned and developed by the authors and revised by one member from each of three patient groups, and the final version was constructed in a 'Survey Monkey'. Before the launch, the survey was tested for technical functionality by three of the authors, and then sent by email.

The questionnaire comprised 22 questions organised in five sections: the first was designed to provide an overview of respondents and the group's involvement in clinical research (6 questions); the second section regarded knowledge of the current debate on IPD sharing and any official position taken by the group ( 5 questions); the third was about who should have access to IPD data and possible mechanisms (2 questions); the fourth section was about risks and advantages of IPD data sharing (3 questions). Six final questions were aimed at describing the respondents' group better. The online supplementary appendix 1 reports an English translation of the introduction to the survey and questionnaire.

As illustrated in figure 1, some questions were conditional on specific answers, that is, applicable only to respondents who provided a specific answer to a previous question. Questions 1 to 7 were aimed at all respondents to gather a minimum of meaningful information about each group. Question 7 'Is your association aware about the current debate on sharing and access to individual participant data from clinical studies?' triggered different pathways of questions. Questions on who should have 


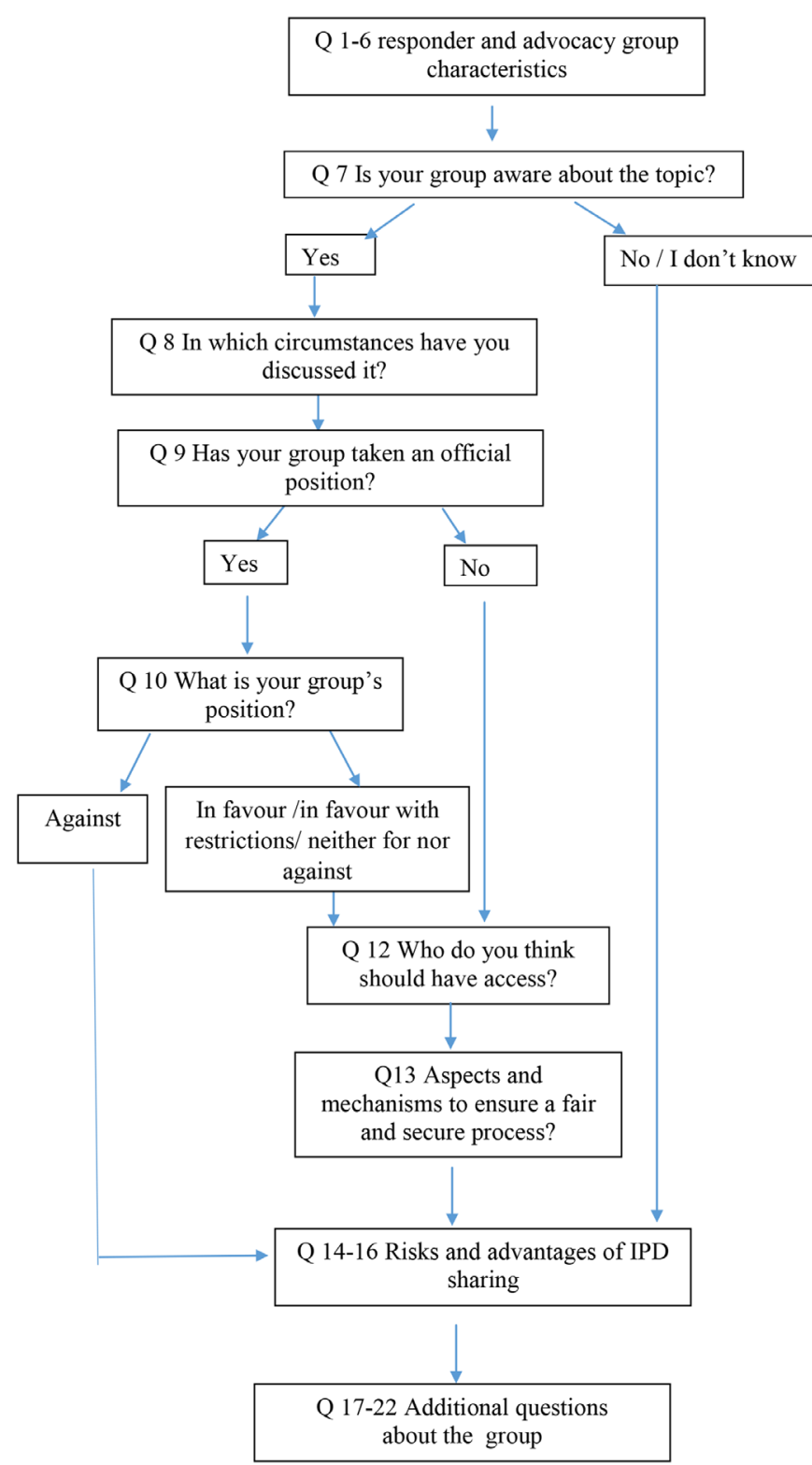

Figure 1 Pathways of questions. IPD, individual participant data.

access to IPD data and possible mechanisms for fair and secure access (questions 12 and 13) were addressed only to groups with a knowledge about the subject and who were not against IPD data sharing. We deemed it interesting to address the questions about IPD sharing risks and advantages (questions 14-16) to all the respondents, irrespective of their knowledge about data sharing.

\section{Survey sample}

In Italy, there is no national comprehensive database of patient and citizen groups. Therefore, we sent the survey to all the groups listed in a large database established at the Laboratory for Research on Consumer Involvement of the Istituto di Ricerche Farmacologiche Mario Negri IRCCS in Milan. ${ }^{27}$ Patient and citizen groups in Italy are fragmented and vary over time and in different areas, making it difficult to draw up a complete list and keep it updated. We identified groups from online searches (for instance, using keywords such as patient groups, patient association, citizen association, plus terms related to specific diseases), public institution websites (Ministry of Health, Italian Revenue Agency, regional and local health agencies), lists reported in books and reports, personal contacts, and patient and citizen groups already working with the Laboratory. The database is updated through revisions of these searches, email or phone calls to patient and citizen groups, and personal contacts. We refer to patients and citizens groups, as the database contains groups that deal with a given disease or condition (lobbying, healthcare assistance and so on) and community-oriented groups that advocate for healthcare rights of people, often referred to as citizens or consumers.

Patient groups in the database vary widely, in their spectra of disease areas, as for instance cancer, diabetes, neurological diseases, HIV; their expertise in clinical research promotion, lobbying and support to patients and their families. Some groups act only locally and regionally. Citizen groups vary too, particularly in terms of their area of activity and expertise in clinical research promotion.

\section{Survey procedure}

Although no login or password was required to access the survey, the link to the questionnaire was sent by email to a specific list of patient and citizen groups, so it was restricted to the invited groups. An invitation message and a brief explanation of IPD sharing clarifying that respondents were being asked to answer on behalf of their group, and the aim of the survey, were sent, together with the link to the web questionnaire (online supplementary appendix 1). Patient and citizen groups could voluntarily respond to the survey over 4 months, from 22 June 2017 to 3 November 2017. Four reminders were sent by email to non-respondents: two times in July, 10 and 20 days after the initial mailing, then two times in October.

The survey did not collect respondents' name or other personal information, and no cookies were used to assign a user identifier; the Internet Protocol (IP) address of respondents was not checked. In the invitation email and in the introduction to the survey, we explained that the data were to be analysed for research purposes and that the Istituto di Ricerche Farmacologiche Mario Negri IRCCS was responsible for data collection and management. We specified that the project and its findings were going to be published in scientific articles. In view of the nature of this survey, no ethics committee approval was required, under Italian law.

\section{Data analysis}

The answers to each question were collected and summarised as numbers and percentages. We established in advance that a questionnaire would be considered eligible for analysis if respondents provided a minimum set of information answering the first seven questions (online supplementary appendix 1). Incomplete eligible 
questionnaires, that is, eligible questionnaires which were terminated early and did not answer all 22 questions, were included in the analysis. The denominator for each question was different due to missing data. The frequency of answers differs from question to question because of both non-respondents and conditional questions. As we did not record respondents' IP addresses, potential duplicate entries were checked manually, comparing the name of the group and its main characteristics (number of members, field of interest and so on). If there was more than one questionnaire regarding the same group, we used the following criteria to select one entry out of duplicates: first, we considered the most completed questionnaire; second, the questionnaire filled in by the president over other roles; third, the questionnaire submitted earliest.

We analysed eligible questionnaires using SAS V.9.4.

\section{Patient involvement}

Before launching the survey, we contacted by phone or email three members of three patient groups to collect their comments on whether a survey on IPD sharing could be of interest for Italian patient and citizen groups. We then sent them a draft of the questionnaire and the introductory text and collected their specific revisions and comments. Feedbacks regarded the clarity of terms, such as transparency in the context of clinical research, the request for adding examples, length and layout. Most suggestions were included in the final versions while, because of space limits, examples were provided by linking the survey to an online article (see the online supplementary appendix 1).

\section{RESULTS}

Out of 2003 email contacts reached, 295 single groups participated in the survey (overall response rate 15\%). We excluded 15 questionnaires as they did not answer the first 7 questions, and analysed the 280 eligible questionnaires. Figure 2 shows the number of patient and citizen groups invited, those who responded, the number of single questionnaires, and the number of eligible and analysed questionnaires. The online supplementary appendix 2 reports the number of responses to each question.

The presidents or vice-presidents of the patient and citizen groups provided the answers in more than two-thirds of the questionnaires analysed.

\section{Characteristics of respondents}

Table 1 reports the main characteristics of patient and citizen groups that responded to the survey. One-third of the respondents were from groups dealing with oncological diseases and palliative care. Thirty-seven per cent had fewer than 100 members and the majority operated at the local or regional level. The patient and citizen groups that responded to the survey were mainly involved in education and dissemination of information and health and social support (eg, home care, access to services).

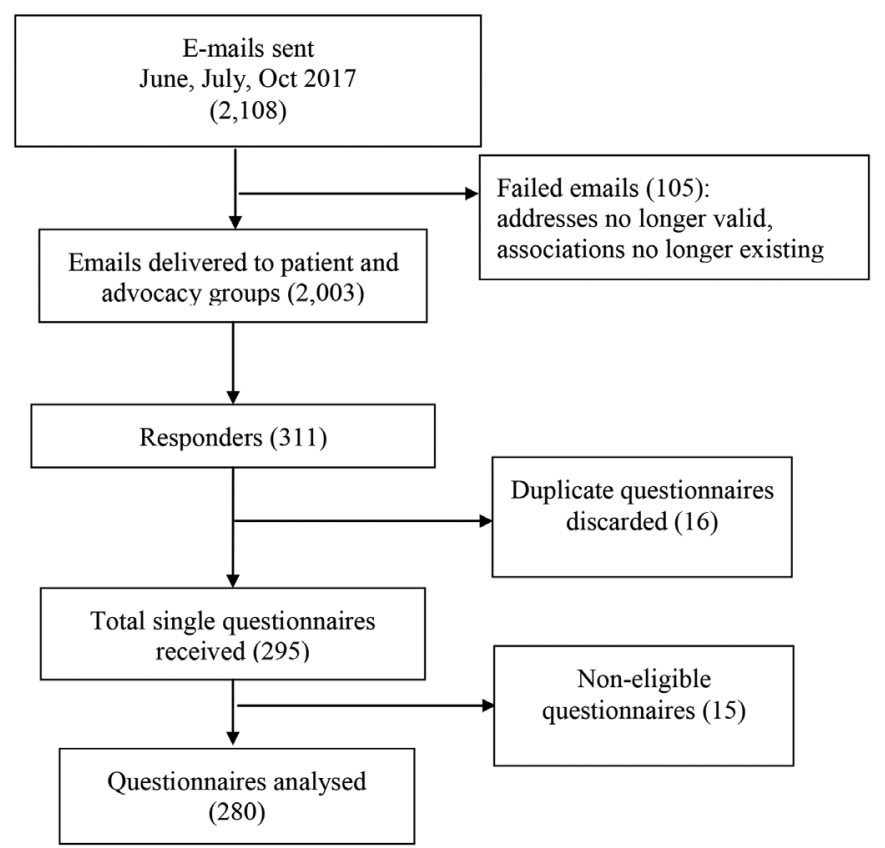

Figure 2 Flow diagram: patient and citizen groups invited, questionnaires received and analysed.

Forty per cent (109 of the 280) said that they provided some form of financial support for research. About half the respondents declared that patients and citizens were the majority of their executive board members, while in about $10 \%$, patients and citizens were a minority or not included in the board. Annual membership fees, donations and bequests were the most common financial sources.

\section{Involvement in clinical research}

About half the responders were involved to some extent in clinical research (136 out of 280, 48.6\%), mainly promoting trial recruitment (71), defining study design (47) and setting priorities for funding (38) (multiple options were possible).

\section{Awareness about IPD sharing and overall view}

Half the respondents $(144,51.4 \%)$ had some knowledge about the current debate on IPD sharing. Discussion about the topic had been encouraged mainly by meetings and conferences with medical societies, researchers, physicians $(84,58.3 \%)$ and individual members of the association as lay members of ethics committees $(35,24.3 \%)$. Some groups $(19,13.2 \%)$ discussed the topic, encouraged by our survey. As expected, the groups involved in clinical research were more aware of the debate than those not involved (83 vs $55,60.1 \%$ vs $39.9 \%$, post hoc exploratory analysis). Among the respondents who declared some knowledge about the issue, $60(41.7 \%)$ stated that their association had taken an official position in the debate. Of these, $35(58.3 \%)$ classified their position as in favour of IPD sharing, $19(31.7 \%)$ in favour but with some restrictions, 2 against and 1 neither for nor against (three missing). 
Table 1 Characteristics of respondent patient and citizen groups (280).

No. (\%)

\section{Field of interest}

Oncology and palliative care

$90(32.1)$

Diabetes

Relationship difficulties and/or mental disabilities

39 (13.9)

$24(8.6)$

Neurological disease

$17(6.1)$

Genetic disorders

Cardiovascular diseases

Citizen groups

Infectious diseases

Rare diseases

Haematological diseases

Autoimmune diseases

Respiratory diseases

Other

Number of members in 2016

$<100$

$100-500$

501-1000

$>1000$

No information

Executive board composition

Patients or citizens are the majority

Patients or citizens are half of the members

Patients or citizens are the minority (or not represented)

Other

$17(6.1)$

$14(5.0)$

$13(4.6)$

$13(4.6)$

$11(3.9)$

7 (2.5)

$6(2.1)$

$5(1.8)$

$24(8.6)$

105 (37.5)

$81(28.9)$

$18(6.4)$

$34(12.1)$

$42(15.0)$

$131(46.8)$

$37(13.2)$

$31(11.1)$

$39(13.9)$

$42(15.0)$

No information

\section{Main sources of funding*}

Annual subscriptions, membership fees, donations, bequests

Public funding (central, regional, local)

Funding from pharma or medical device companies

Funding from other commercial entities

Bank foundations

Other

No information

$209(74.6)$

$72(25.7)$

$54(19.2)$

$24(8.5)$

$8(2.8)$

35 (12.5)

41 (14.6)

\section{Type of activities}

Education and dissemination/information

Yes

$206(73.6)$

7 (2.5)

No

$26(9.3)$

To some extent

$41(14.6)$

Financial support for research

Yes

$51(18.1)$

No

$123(43.9)$

$58(20.7)$

$48(17.1)$

\section{Table 1 Continued}

No. (\%)

Lobby at the institutional level (local and central)

Yes

52 (18.6)

No

$130(46.4)$

To some extent

49 (17.5)

No information

49 (17.5)

Fund-raising

Yes

$86(30.7)$

No

$44(15.7)$

To some extent

105 (37.5)

No information

45 (16.1)

Health/social support (eg, home care, access to services and so on)

Yes

$132(47.1)$

No

$53(18.9)$

To some extent

49 (17.5)

No information

46 (16.4)

Surveys about health services

Yes

$42(15.0)$

No

89 (31.8)

To some extent

$100(35.7)$

No information

49 (17.5)

Area of activity

Local

$110(39.3)$

Regional

65 (23.2)

National

64 (22.9)

No information

41 (14.6)

Member of international network

Yes

$99(35.4)$

No

$140(50)$

No information

41 (14.6)

*More than one answer possible, so the sum of responses is over $100 \%$.

Views on access, mechanisms and guarantees for IPD sharing Respondents who declared some knowledge on the ongoing debate and were not against IPD sharing (142, $50.7 \%$ ) were asked to indicate who should have access to IPD. Many supported broad access (56 out of 142, 39\%), not only restricted to researchers but open to other groups and individuals such as patients' and citizen group representatives and journalists (figure 3).

They were also asked about their opinions on how to ensure a fair IPD sharing and re-use mechanism. The aspects of the process considered most important were information in a patient leaflet (informed consent sheet) and de-identification of data before sharing, followed by the security of data storage repositories and the existence of agreements between data generators and data re-users and possible sanctions in case of data misuse (figure 4). 
Researchers, representatives from patients' and citizens' associations, journalists, etc.

Only researchers presenting a clear, complete and relevant research question

Only researchers from public or not-for-profit institutions

All researchers from public or private institutions (including for example those from the pharma industry)

Only researchers presenting a research question that has no clear commercial interest

I don't know

0
10

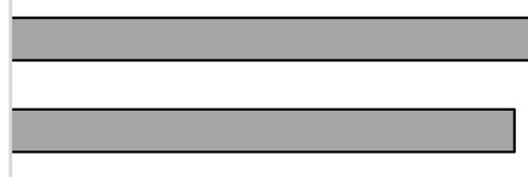

38

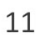

11

20

30

40

50

60

Figure 3 Who do you think should have access?

\section{Number of responders}

\section{Risks and advantages of IPD sharing}

Patients and citizen groups, irrespective of their knowledge about data sharing, were asked to indicate their position on possible risks and advantages. The majority highlighted re-identification and privacy and the re-use of data for purposes that trial participants do not approve as the main risks (146 and 138 responses, respectively). The minority did not foresee any risk ( 47 responses). Advancement of innovation and re-use of data to reduce waste in research were cited as the main advantages of IPD data sharing, followed by the possibility of studying adverse reactions and side effects of treatments (figure 5).
Around half the respondents (144 of 258, 55.8\%) believed IPD sharing from clinical studies would not discourage people from participating, while a quarter said they did not know (61 out of 258, 23.6\%).

A post hoc exploratory analysis showed that groups that knew about the IPD sharing debate were more concerned about privacy and risk of re-identification than those who did not know ( 90 vs $56,61.6 \%$ vs $38.4 \%$ ), and more often considered IPD sharing advantageous to reduce unnecessary research (94 vs $64,59.5 \%$ vs $40.5 \%)$ and to study adverse reactions to treatments ( 70 vs $47,59.8 \%$ vs $40.2 \%)$.

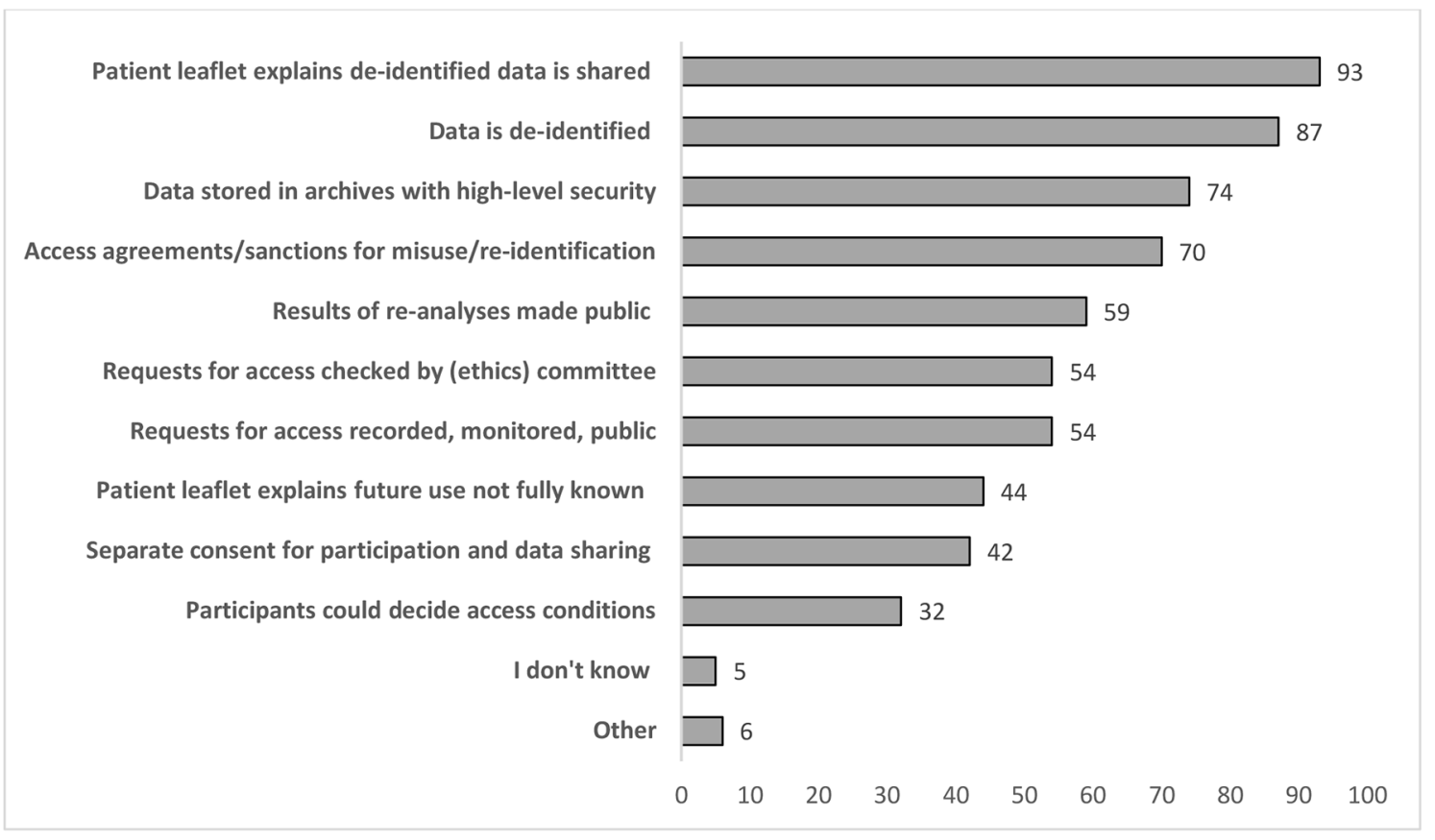

\section{Number of responses}

Figure 4 Aspects important to ensure a fair and secure process (more than one answer possible). 


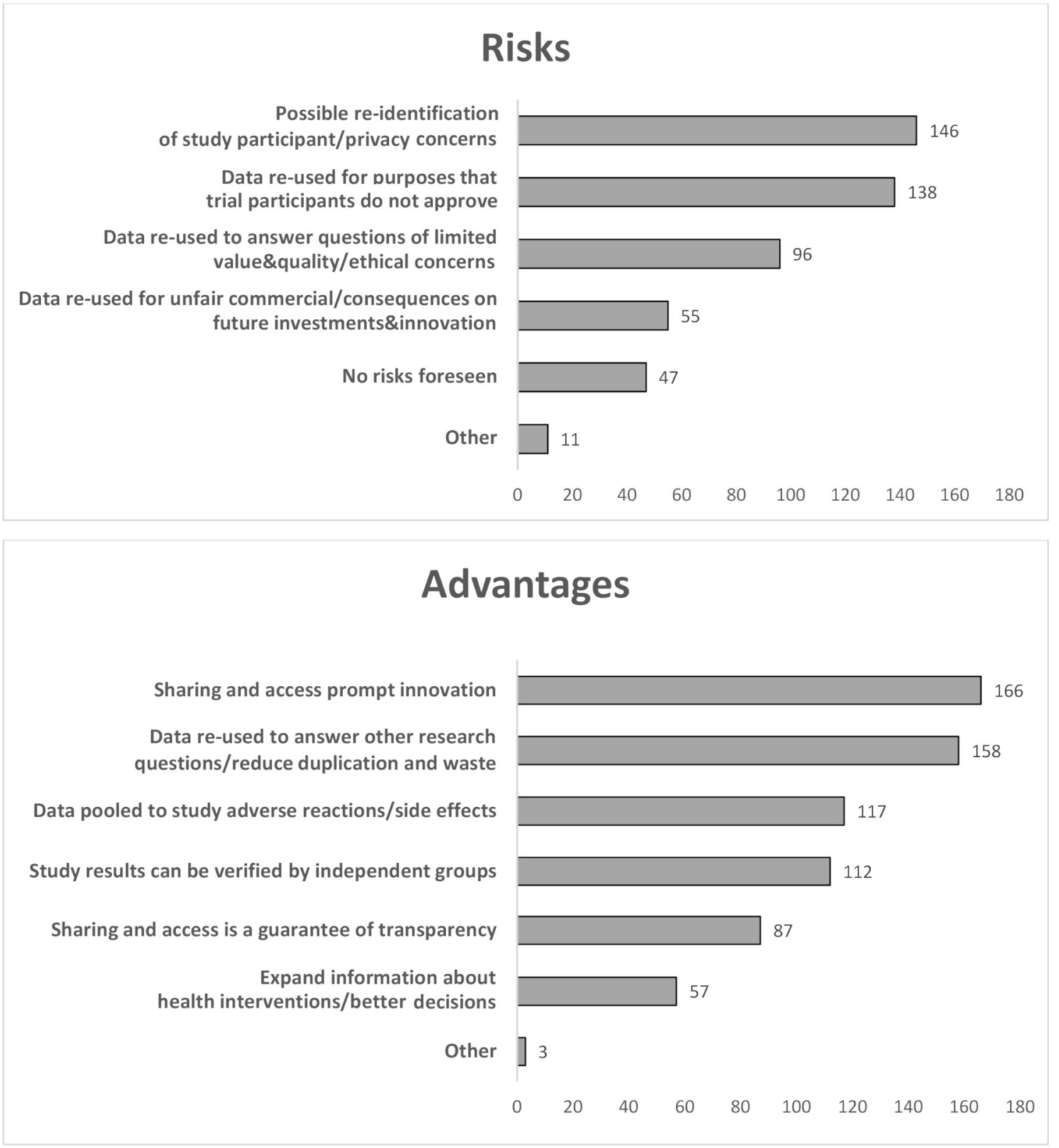

\section{Number of responses}

Figure 5 Risks and advantages of individual participant data sharing (more than one answer possible).

\section{DISCUSSION}

This survey provides information on the knowledge, opinions and attitudes of a sample of Italian patient and citizen groups regarding sharing data generated in clinical studies. IPD sharing is a global issue that raises ethical, juridical and legislative questions that may differ in different countries. Country-specific analyses would, therefore, be useful to highlight cultural and social factors that could play a role in shaping data sharing practices.

Half the groups who responded to our survey said that they were aware of the current debate on IPD sharing, and a minority had an official position on the issue. About $40 \%$ of the respondents supported broad access where researchers, representatives of patients' and citizens' associations, journalists and others could have access to de-identified IPD. In line with the preference for broad access, respondents seem not to exclude re-use of data for research questions having a commercial interest. Respondents were mainly in favour of IPD sharing under specific conditions, as in other studies. ${ }^{32}$ Clear information provided to trial participants, processes and mechanisms to reduce the risk of data de-identification, access agreements and sanctions in case of data misuse, transparency and public disclosure on access requests and results were the conditions most often required. Separate informed consent for data sharing was less frequently indicated as a priority. This may be related to the lower value assigned to a separate form or, more broadly, to the perception of the importance of the informed consent form itself. 
These aspects are important for building trust in entities and organisations that would handle IPD sharing and reuse. As frequently noted in the literature, trust informs the level of support for research uses of data, together with public engagement and involvement, considered essential for ensuring accountability. ${ }^{32}$

When asked about the risks and advantages of data sharing, respondents indicated privacy issues and re-use of data for purposes that trial participants did not approve as major risks, and the promotion of innovation and reduction of duplication and waste of resources as major advantages. A study in the USA involving clinical trial participants got similar results in terms of advantages: one of the most important benefits perceived was to get answers to scientific questions faster. Results were quite different in terms of concerns. More than 35\% in that study were concerned that IPD sharing could discourage people from participating in clinical studies, ${ }^{38}$ while a fifth of the respondents in our study stated that IPD sharing might discourage people from participating. Another US survey ${ }^{37}$ got a similar result: $25 \%$ of respondents stated they would be less likely to take part in a clinical trial. One may hypothesise that trial participants are more concerned as the question regards their own data, while patients or groups consider this a more hypothetical question.

Although limited by the low response rate, our findings highlight the importance of two concepts. First, all the steps that make up the process of data sharing should be reliable and transparent. For instance, responses about the security of data storage repositories, sharing agreements and possible sanctions in case of data misuse are requests for a clear definition of responsibilities (accountability and reliability). Public reporting of data access requests and results of re-analyses represent a call for transparency. Second, data sharing should promote the development of new and better interventions and optimise research efforts. IPD sharing is likely to become more acceptable if processes are fairly planned and described and the underlying assumptions explained, respecting the rights of trial participants and honouring their efforts, maximising the value of their data.

One strength of the study is that even those not familiar with the ongoing discussion regarding IPD sharing answered the survey and provided their opinions. When asked about what triggered the discussion on IPD sharing, some groups actually stated that the survey itself encouraged them to start.

As the survey was aimed at collecting the views of patient groups rather than those of individuals, we sent invitations to the official address of the president, when available, or the secretary, and clearly asked them, in the email and in the introduction, to respond on behalf of the group. In fact, the president or vice-presidents responded to more than two-third of the eligible questionnaires. Despite these efforts, a small percentage of responders may have provided their individual perspectives.
The main limitations-like in similar surveys-are the representativeness of the respondents and the low response rate. Patient and citizen groups in Italy are a moving target. Contact persons change, some groups close and others open within a short time, and thus it requires frequent effort to keep our database up-to-date (105 emails bounced back because addresses were no longer valid or associations no longer existed). Moreover, we cannot completely exclude that the database contains a limited number of multiple addresses for the same group, so the 2,003 emails sent would not correspond to the same number of associations. To be conservative, we calculate the response rate on the basis of the number of emails sent. The low response rate may be due to several factors, including lack of interest or familiarity with the topic, lack of time or surveys' overload. We opted for a broad approach and invited all the groups listed in the database to participate, rather than focus on the bigger national groups or federations. This might have reduced the response rate as the topic might have been perceived as not related to the area of interest of some groups, especially those acting locally. However, it allowed us to explore the level of awareness and possibly raise the level of attention on the topic in all the groups. We could not assume that local patient and citizen groups were simply not interested or somehow involved in the debate, and in fact, about $40 \%$ of the respondents were active at the local level.

The changing landscape and the lack of a national inventory of all the Italian patient and citizen groups also meant that we could not fully define the characteristics of the groups we contacted and the profile of non-respondents. It is likely that the responses came from groups that were more interested in clinical research, and perhaps even more in favour of IPD sharing. However, we could not exclude that those that were against IPD sharing decided to participate to express their disagreement. Our ability to characterise the sample of respondents was also affected by the rate of missing information in some of the final questions, for example, number of members, composition of the advisory board and so on (table 1 and online supplementary appendix 2). We decided to put these questions in the final part of the questionnaire as we considered them less important than those dealing with the core topics of the survey - regarding IPD sharing. As the length of the survey could have discouraged respondents from going through the whole questionnaire, we put the main questions at the beginning; respondents may, in fact, have been discouraged by the length or due to the lack of information on some questions.

The topic of IPD sharing from clinical studies is complex and is not a matter of general public discussion in Italy. We tried to balance the aim of gathering an overall picture with the collection of opinions on specific points related to IPD sharing. We included an explanation at the beginning of the questionnaire and several questions had multiple options for answers. These options and their wording may have influenced 
the respondents, particularly for groups that stated that the survey itself had encouraged their discussion on data sharing. However, we included the 'other' option to allow for alternative ideas or opinions.

More action is needed to disseminate the value of IPD sharing, address the challenging issues of privacy, data ownership and access, and boost knowledge and discussion among patient and citizen groups. If some are reluctant to share their health data, others are already sharing their data through databases managed directly by patient groups. A growing number of people with specific disorder or disease want to be involved in clinical research, consenting to participate in clinical studies and having a voice in shaping the research agenda. ${ }^{40}$

Like in other debates, citizens, patients and their representatives play a valuable role only if they are substantially engaged. ${ }^{41}$ For instance, patient and citizen groups may participate in defining procedures for IPD sharing or sit on committees that assess requests for accessing IPD as part of controlled processes. The best strategies to promote their engagement still need to be identified and evaluated. ${ }^{42}$

Clear, specific information on the risks and advantages of data sharing have to be stated as a prerequisite to engage the public, citizens and patients, fostering a public dialogue on data sharing. ${ }^{43}$ The tension between individual autonomy of participants providing data and bio-samples in clinical studies and the social value of clinical research, data ownership and who decides the balance between individual and community rights are aspects that must be addressed. ${ }^{17}$

Further evidence is needed on what patients and citizens think about clinical study data sharing and understand their interest in the topic better. Recently completed surveys of Cochrane Consumer Network members and Cochrane Croatian partner organisations ${ }^{445}$ could help inform the debate.

We also need a thorough analysis of the answers provided by responding groups to catch their opinions and attitudes better and share proposals to face all the issues. Meetings and workshops with multiple stakeholders (patient and citizen groups, researchers, charities and foundations) or semistructured interviews aimed at responding groups may serve these purposes. More structured training sessions could strengthen the engagement of patient and citizen groups and their contributions to the discussion. ${ }^{46}$ It could be useful to focus on the exploratory finding that privacy and risk of re-identification were most often cited as risks by the groups knowing about IPD sharing in order to drive future surveys and activities with patient and citizen groups.

\section{CONCLUSIONS}

This study found that half of the Italian groups who responded to the survey were aware of the debate on IPD sharing and a minority had an official position. Respondents were mainly in favour of IPD sharing under specific conditions, asking for reliable and transparent processes to reduce the risk of de-identification, define access agreements and disclose access requests and results.

Author affiliations

${ }^{1}$ Department of Public Health, Laboratory for Medical Research and Consumer Involvement, Istituto di Ricerche Farmacologiche Mario Negri IRCCS, Milan, Italy ${ }^{2}$ IMPACT Observatory, Visiting Scientist MedILS (Mediterranean Institute for Life Sciences), Split, Croatia

${ }^{3}$ Cochrane Croatia, Split, Croatia

${ }^{4}$ Electronic Health Information Laboratory, CHEO Research Institute, Ottawa, Ontario, Canada

${ }^{5}$ Department of Epidemiology, Lazio Regional Health Service - ASL Roma 1, Rome, Italy

${ }^{6}$ Center for Regulatory Policies, Istituto di Ricerche Farmacologiche Mario Negri IRCCS, Milan, Italy

Acknowledgements The authors thank Claudio Castegnaro Fondazione Paracelso Giulio Maria Corbelli, Plus onlus LGBT people living with HIV, Massimo Oldrini LILA -Italian League for the Fight against AIDS- for revising the questionnaire, Gianna Costa for collaboration in survey invitations, Paola Mosconi and Maurizio Bonati for their comments on earlier versions of the manuscript, and J D Baggott for editing.

Contributors CC and RB: proposed the survey and drafted the questionnaire. KK-J, EP and AR: contributed to the final questionnaire. CC and AR: launched the survey, managed the reminders and the data collection. AR: analysed the data. CC, AR and RB: interpreted the data. CC and RB: drafted the manuscript. KKJ, EP and AR: substantially contributed to its content. All the authors approved the final manuscript.

Funding It was supported by internal funds of the Istituto di Ricerche Farmacologiche Mario Negri IRCCS in the context of the EU Horizon 2020 CORBEL project (grant agreement number 654248).

Competing interests None declared.

Patient consent for publication Not required.

Ethics approval In view of the nature of this survey, no ethics committee approval was required, under Italian law. We asked patient and citizen groups' representatives to answer in the name of their groups. No personal names were collected, no cookies were used to assign a user identifier, and the IP address of respondents was not checked. We specified in the e-mail and in the introduction to the survey that the data were collected for research purposes, and that the Istituto di Ricerche Farmacologiche Mario Negri IRCCS was responsible for data collection and management. Participation in the survey was free and voluntary; participants actively chose to respond.

Provenance and peer review Not commissioned; externally peer reviewed.

Data sharing statement The corresponding author will made available the dataset on request.

Open access This is an open access article distributed in accordance with the Creative Commons Attribution Non Commercial (CC BY-NC 4.0) license, which permits others to distribute, remix, adapt, build upon this work non-commercially, and license their derivative works on different terms, provided the original work is properly cited, appropriate credit is given, any changes made indicated, and the use is non-commercial. See: http://creativecommons.org/licenses/by-nc/4.0/.

\section{REFERENCES}

1. Chan AW, Song F, Vickers A, et al. Increasing value and reducing waste: addressing inaccessible research. Lancet 2014;383:257-66.

2. International Organization for Migration. Sharing clinical trial data: maximizing benefits, minimizing risk. Washington: International Organization for Migration, 2015.

3. Kiley R, Peatfield T, Hansen J, et al. Data sharing from clinical trials a research funder's perspective. N Engl J Med 2017;377:1990-2.

4. Tudur Smith C, Hopkins C, Sydes MR, et al. How should individual participant data (IPD) from publicly funded clinical trials be shared? BMC Med 2015;13:298.

5. Ohmann C, Banzi R, Canham S, et al. Sharing and reuse of individual participant data from clinical trials: principles and recommendations. BMJ Open 2017;7:e018647. 
6. Devereaux PJ, Guyatt G, Gerstein H, et al. Toward fairness in data sharing. N Engl J Med 2016;375:405-7.

7. Taichman DB, Sahni P, Pinborg A, et al. Data sharing statements for clinical trials. BMJ 2017;357:j2372.

8. PHRMA, EFPIA. Principles for responsible clinical trial data sharing 2014. http://phrma-docs.phrma.org/sites/default/files/pdf/PhRMAPri nciplesForResponsibleClinicalTrialDataSharing.pdf

9. Naudet F, Sakarovitch C, Janiaud P, et al. Data sharing and reanalysis of randomized controlled trials in leading biomedical journals with a full data sharing policy: survey of studies published in The BMJ and PLOS Medicine. BMJ 2018;360:k400.

10. Rowhani-Farid A, Barnett AG. Has open data arrived at the British Medical Journal (BMJ)? An observational study. BMJ Open 2016;6:e011784.

11. Savage CJ, Vickers AJ. Empirical study of data sharing by authors publishing in PLoS journals. PLoS One 2009;4:e7078.

12. Rockhold F, Nisen P, Freeman A. Data sharing at a crossroads. $N$ Engl J Med 2016;375:1115-7.

13. Haug CJ. Whose data are they anyway? Can a patient perspective advance the data-sharing debate? N Engl J Med 2017;376:2203-5.

14. Destro Bisol G, Anagnostou P, Capocasa M, et al. Perspectives on open science and scientific data sharing:an interdisciplinary workshop. J Anthropol Sci 2014;92:179-200.

15. Antman EM, Benjamin EJ, Harrington RA, et al. Acquisition, analysis, and sharing of data in 2015 and beyond: a survey of the landscape: a conference report from the american heart association data summit 2015. J Am Heart Assoc 2015;

16. Krleza-Jeric K. International dialogue on the public reporting of clinical trial outcome and results - PROCTOR meeting. Croat Med J 2008;49:267-8

17. Tallacchini M. From biobanks to genetic digital networks: why official pre-identified values may not work. In: Guimaraes Pereira A, Funtowicz S, eds. Science, philosophy and sustainability the end of the cartesian dream. Routledge, 2015:98-111.

18. World Medical Association. World Medical Association Declaration of Helsinki: ethical principles for medical research involving human subjects. JAMA 2013;310:2191-4.

19. Krleza-Jeric K. Sharing of clinical trial data and research integrity. Periodicum Biologorum 2014;116:337-9.

20. Liberati A. So many questions, so few answers. Interview by Les Olson. Bull World Health Organ 2010;88:568-9.

21. Vickers AJ. Whose data set is it anyway? Sharing raw data from randomized trials. Trials 2006;7:15.

22. El Emam K, Rodgers S, Malin B. Anonymising and sharing individual patient data. BMJ 2015;350:h1139.

23. Vayena E, Brownsword R, Edwards SJ, et al. Research led by participants: a new social contract for a new kind of research. $J$ Med Ethics 2016;42:216-9.

24. Streuli JC, Vayena E. The promising revolution of participant led research in neurological disease potential benefits and pitfalls. Epileptologie 2015

25. Dresser R. When science offers salvation: patient advocacy and research ethics. New York: Oxford University Press, 2001.

26. NHS. Patient and public participation policy Head of Programme Delivery. Public Participation Team 2017.

27. Mosconi P, Colombo C, Satolli R, et al. PartecipaSalute, an Italian project to involve lay people, patients' associations and scientific- medical representatives in the health debate. Health Expect 2007:10:194-204.

28. Colombo C, Moja L, Gonzalez-Lorenzo M, et al. Patient empowerment as a component of health system reforms: rights, benefits and vested interests. Intern Emerg Med 2012;7:183-7.

29. European Medicines Agency. Finalisation of the EMA Policy on Publication of and Access to Clinical Trial Data - Targeted Consultation With Key Stakeholders in May 2014. London, 2014.

30. European Medicines Agency. Data anonymisation - a key enabler for clinical data sharing. London, 2017.

31. European Medicines Agency. Access to clinical-trial data and transparency - workshop report. London, 2012.

32. Aitken M, de St Jorre J, Pagliari C, et al. Public responses to the sharing and linkage of health data for research purposes: a systematic review and thematic synthesis of qualitative studies. BMC Med Ethics 2016;17:73.

33. Kim KK, Sankar P, Wilson MD, et al. Factors affecting willingness to share electronic health data among California consumers. BMC Med Ethics 2017;18:25

34. Spencer K, Sanders C, Whitley EA, et al. Patient Perspectives on Sharing Anonymized Personal Health Data Using a Digital System for Dynamic Consent and Research Feedback: A Qualitative Study. J Med Internet Res 2016;18:e66.

35. TNS-BMRB. Open data dialogue, final report, 2012.

36. Tully MP, Bozentko K, Clement S, et al. Investigating the extent to which patients should control access to patient records for research: a deliberative process using citizens' juries. J Med Internet Res 2018;20:e112.

37. Jones CW, Roberts BW, Platts-Mills TF. Patient perspectives on sharing deidentified trial data. Ann Intern Med 2016;165:748-9.

38. Mello MM, Lieou V, Goodman SN. Clinical trial participants views of the risks and benefits of data sharing. N Engl J Med 2018;378:2202-11

39. Krleža-Jerić K, Gabelica M, Banzi R, et al. IMPACT Observatory: tracking the evolution of clinical trial data sharing and research integrity. Biochem Med 2016;26:308-07.

40. Bradley M, Braverman J, Harrington M, et al. Patients' motivations and interest in research: characteristics of volunteers for patient-led projects on PatientsLikeMe. Res Involv Engagem 2016;2:33

41. Liabo K, Boddy $\mathrm{K}$, Burchmore $\mathrm{H}$, et al. Clarifying the roles of patients in research. BMJ 2018;361:k1463.

42. Domecq JP, Prutsky G, Elraiyah T, et al. Patient engagement in research: a systematic review. BMC Health Serv Res 2014;14:89.

43. Kostkova $\mathrm{P}$, Brewer $\mathrm{H}$, de Lusignan $\mathrm{S}$, et al. Who owns the data? Open data for healthcare. Front Public Health 2016;4:7.

44. Krleza-Jeric K, Jeric P, Marusic A. Cochrane consumers and data sharing of clinical trials - a survey; IMPACT (IMProving Access to Clinical Trials data) Observatory. Abstracts of the Global Evidence Summit, Cape Town, South Africa. Abstract 19202. Cochrane Database Syst Rev 2017:9(Suppl 1).

45. Zakarija-Grkovic I, Buljan I, Drandic D, et al. Cochrane Croatia's collaboration with partner patient/consumer organisations: use of Cochrane evidence, expectations, and opinions on data sharing Abstracts of the 25th Cochrane Colloquium, Edinburgh, UK Cochrane Database of Systematic Reviews 2018;303.

46. Mosconi P, Satolli R, Colombo C, et al. Does a consumer training work? A follow-up survey of the PartecipaSalute training programs. Health Res Policy Syst 2012;10:27. 